\title{
A construção de saberes através da educação permanente na atenção básica à saúde: relato de experiência
}

Nayara Rodrigues Carvalho, Luana Vieira Toledo, Erika Andrade e Silva, Júlia Borges Figueiredo, Amanda Silva Cardoso Estevão, Deíse Moura de Oliveira

\begin{abstract}
Resumo
O Ministério da saúde criou, em 2004, a Política Nacional de Educação Permanente em Saúde que prevê estratégias para a formação e o desenvolvimento dos profissionais atuantes no SUS, propondo processos educativos descentralizado, ascendente e transdisciplinar. Almeja-se uma transformação da prática profissional subsidiada no seu processo de trabalho, onde haja uma corresponsabilização do cuidado entre os profissionais e os usuários do serviço. Essa corresponsabilização ainda se configura como um grande desafio, sobretudo para os técnicos de enfermagem. Esse desafio reforça a necessidade das atividades reflexivas como as de educação permanente (EP), consideradas como práticas profissionais baseadas na crítica sobre as reais atividades executadas na rede de serviços. Neste sentido, a EP visa transformar o processo de trabalho, de modo a qualificar as práticas de saúde nos serviços, assim, acredita-se que a EP com os técnicos de enfermagem possibilitará a reconfiguração das práticas desses profissionais no âmbito da Atenção Básica de Saúde (ABS). Relatar a experiência de uma atividade de extensão universitária realizada com técnicos de enfermagem da Estratégia Saúde da Família (ESF) do município de Viçosa -MG. O Programa de Educação Permanente com técnicos de enfermagem consiste em um projeto de extensão vinculado à Universidade Federal de Viçosa (UFV) no qual são realizadas oficinas educativas a partir da demanda vivenciada na prática por esta categoria profissional. A equipe do projeto é constituída de docentes e acadêmicos de curso de enfermagem da UFV, os quais organizam as atividades de concentração e dispersão, com visitas aos técnicos de enfermagem em suas respectivas unidades, a fim de fortalecer os conhecimentos e reflexões construídos nas oficinas mensais. No primeiro encontro foram abordadas as atribuições dos técnicos de enfermagem, segundo a Política Nacional de Atenção Básica. As demais oficinas foram planejadas a partir da aplicação de um questionário que permitiu levantar as demandas de conhecimento da categoria, sendo os temas elencados para os próximos encontros: classificação e manejo de feridas, atribuições do técnico de enfermagem na assistência à saúde da criança, com enfoque na Imunização. A partir das ações do projeto pode-se perceber um fortalecimento da parceria e diálogo entre a gestão, ensino e serviço. Além do aumento do vínculo e corresponsabilização entre os técnicos de enfermagem, universidade e gestão, estabelecendo um espaço para discussão e reflexão das dificuldades e facilidades encontradas no cotidiano de serviço. Merece grande destaque, o sentimento de valorização profissional proporcionado a esta categoria, evidenciado na adesão e participação ativa destes nas atividades desenvolvidas. O projeto apresenta-se como uma potencial ferramenta para a educação permanente dos técnicos de enfermagem, que se percebem exclusos da ESF. O processo de construção e desconstrução entre acadêmicos e técnicos de enfermagem promovem um aprendizado que reflete positivamente na prestação de um cuidado integral e humanizado ao indivíduo, família e comunidade.
\end{abstract}

Descritores: Educação Permanente, Técnicos de Enfermagem, Estratégia Saúde da Família. 